\title{
Experimental and theoretical investigation of electro-optic and all-optical implementations of wavelength converting $2 \mathrm{R}$-regenerators
}

Wolfson, David; Mikkelsen, Benny; Danielsen, Søren Lykke; Poulsen, Henrik Nørskov; Hansen, Peter Bukhave; Stubkjær, Kristian

Published in:

Technical Digest Optical Fiber Communication Conference and Exhibit

Link to article, DOI:

10.1109/OFC.1998.657246

Publication date:

1998

Document Version

Publisher's PDF, also known as Version of record

Link back to DTU Orbit

Citation (APA):

Wolfson, D., Mikkelsen, B., Danielsen, S. L., Poulsen, H. N., Hansen, P. B., \& Stubkjær, K. (1998). Experimental and theoretical investigation of electro-optic and all-optical implementations of wavelength converting 2R-

regenerators. In Technical Digest Optical Fiber Communication Conference and Exhibit (pp. 103-105). IEEE. https://doi.org/10.1109/OFC.1998.657246

\section{General rights}

Copyright and moral rights for the publications made accessible in the public portal are retained by the authors and/or other copyright owners and it is a condition of accessing publications that users recognise and abide by the legal requirements associated with these rights.

- Users may download and print one copy of any publication from the public portal for the purpose of private study or research.

- You may not further distribute the material or use it for any profit-making activity or commercial gain

- You may freely distribute the URL identifying the publication in the public portal 


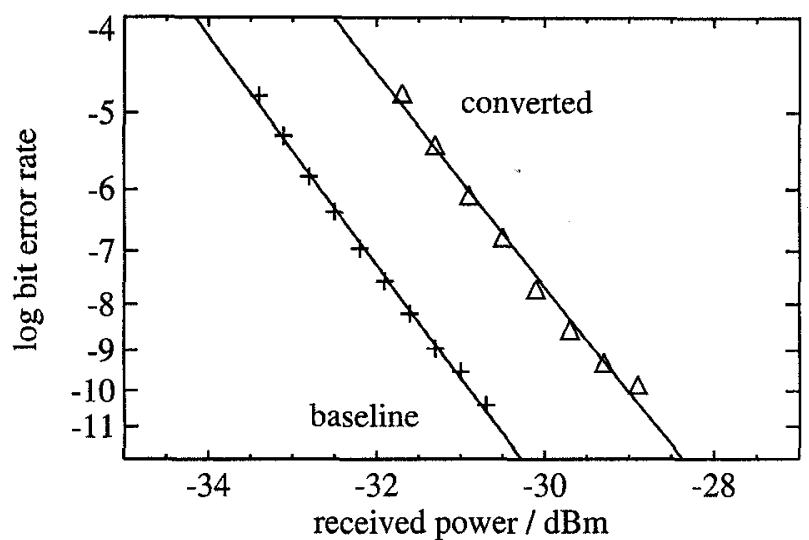

WB2 Fig. 3. BER for conversion of a 1552-nm PRBS of length $2^{23}-1$ to 1560 $\mathrm{nm}$ at $2.5 \mathrm{Gbit} / \mathrm{s}$. The penalty of $2 \mathrm{~dB}$ is caused by a combination of extinction ratio degradation (to $11 \mathrm{~dB}$ ) and intersymbol interference effects. No error floors are observed.

Dynamic operation of the device is demonstrated by means of the bit-error-rate measurements presented in Fig. 3, which show wavelength conversion at $2.5 \mathrm{Gbit} / \mathrm{s}$ from $1552-1560 \mathrm{~nm}$. Although the lossy waveguides limit the speed and thus add to the conversion penalty, a clean and open eye was observed for the converted signal, and error-free wavelength conversion has been obtained.

In summary, a Mach-Zehnder wavelength converter with variable input and output wavelengths has been presented. The integrated signal and probe pre-amplifiers potentially reduce input power requirements. Around $25-\mathrm{dB}$ extinction ratio has been demonstrated, as well as operation at $2.5 \mathrm{Gbit} / \mathrm{s}$.

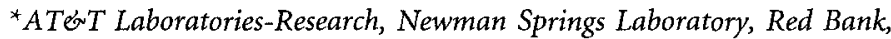
New Jersey 07701

1. K.E. Stubkjaer et al., in Proceedings of 22nd European Conference on Optical Communication (ECOC '96), 1996, pp. 4.33-4.40, and references therein.

2. L.H. Spiekman, U. Koren, M.D. Chien, B.I. Miller, J.M. Wiesenfeld, J.S. Perino, in Optical Fiber Communication Conference, Vol. 6 of 1997 OSA Technical Digest Series (Optical Society of America, Washington, D.C., 1997), paper PD10.

3. L.H. Spiekman, U. Koren, M.D. Chien, B.I. Miller, J.M. Wiesenfeld, J.S. Perino, IEEE Photon. Technol. Lett. 9, (1997).

4. U. Koren, M.G. Young, M. Chien, B.I. Miller, T.L. Koch, K. Dreyer, R.J. Capik, in Proceedings of 8th Eur. Conf. on Int. Opt. (ECIO '97), (April 1997).

Experimental and theoretical investigation of electrooptic and all-optical implementations of wavelength converting 2R-regenerators

D. Wolfson, B. Mikkelsen, S.L. Danielsen, H.N. Poulsen, P.B. Hansen, K.E. Stubkjaer, Center for Broadband Telecommunications, Dept. of Electromagnetic Systems, Technical University of Denmark, Bldg. 348, DK-2800 Lyngby, Denmark

Wavelength-division multiplexing (WDM) networks will require bitrate transparent wavelength converters/adapters to interface fiber links utilizing different sets of wavelengths. Additionally, suppression of noise at the interfaces will be needed. Hence, wavelength converters with a $2 \mathrm{R}$ functionality (re-amplification and re-shaping) are highly desired.

In this paper we investigate and compare the regenerative capability of electro-optic (E/O) wavelength converters based on electrically controlled external Mach-Zehnder (MZ) modulators and all-optical (A/O) wavelength converters based on all-optically controlled external MZmodulators. The latter incorporates semiconductor optical amplifiers (SOAs) as optically controlled phase shifters. ${ }^{1}$ Experiments demonstrate a 5-6 dB noise suppression capability for both the electro-optic and the all-optical implementation of the wavelength-converting regenerators. The performance can be further improved by cascading two converters resulting in $8-\mathrm{dB}$ noise suppression. This is considered a realistic approach for the compact all-optical converter. The experiments are supported by detailed modeling.

The two wavelength converters are shown schematically in Fig. 1. The E/O-converter consists of a detector/front-end, an electronic amplification stage followed by an external $\mathrm{MZ}$ modulator used to modulate a $\mathrm{cw}$-source. $\mathrm{V}_{\mathrm{pp}}$ of the modulator is 4 Volt and the $3-\mathrm{dB}$ modulation bandwidth of the entire converter is $4 \mathrm{GHz}$. The all-optical converter is a polarization-insensitive interferometric wavelength converter where SOAs are monolithically integrated into an interferometric structure. ${ }^{2}$

Due to the sinusoidal transfer function of both converters a noise reduction capability is obtained when they are deployed between noise

\section{Electro-optical converter}

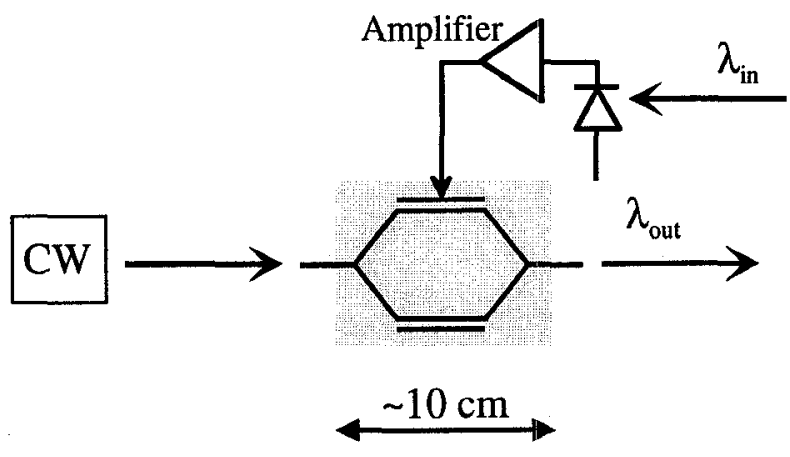

All-optical converter

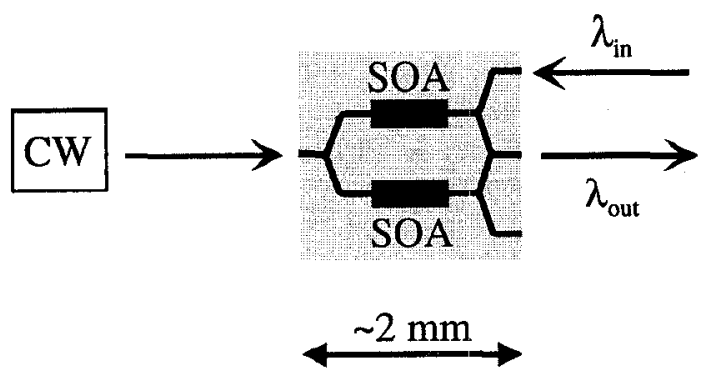

WB3 Fig. 1. Schematic of an electro-optic and all-optical converter. 

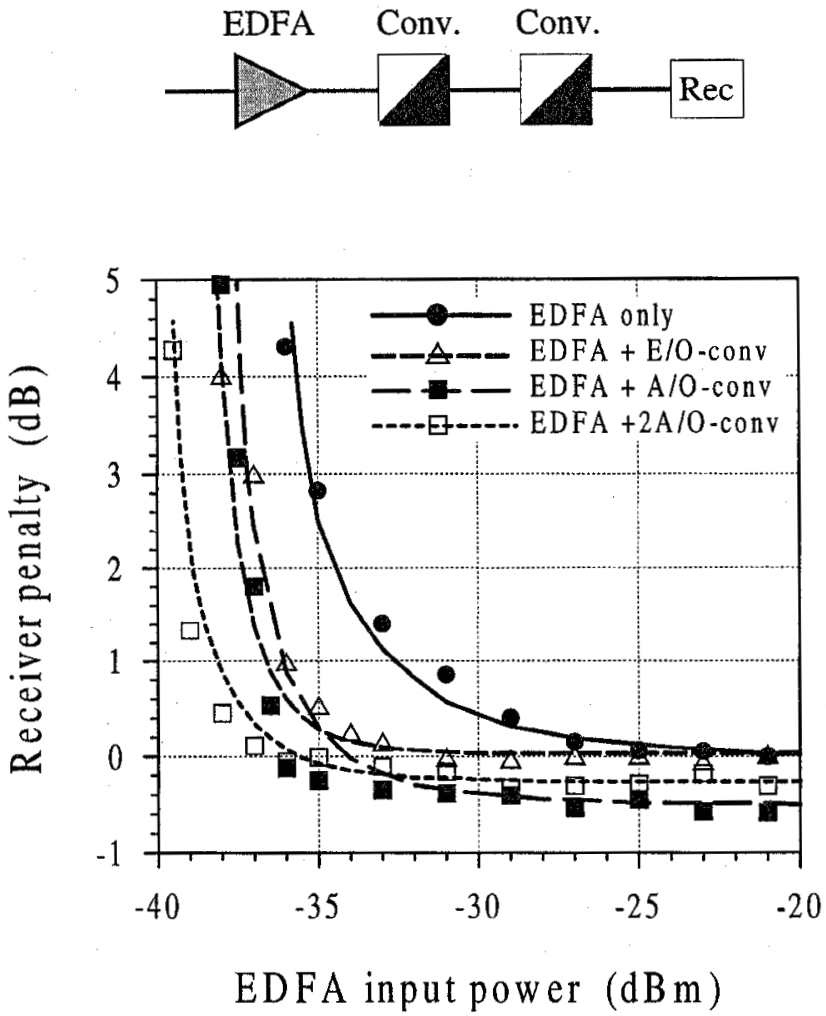

WB3 Fig. 2. Measured and calculated (lines) penalty (@BER $=10^{-9}$ ) vs. input power of the EDFA with EDFA alone and EDFA followed by regenerating converters. E/O: electro-optical, A/O: all-optical.

sources, ${ }^{3,4}$ e.g., erbium-doped fiber amplifiers (EDFAs) adding amplified spontaneous emission (ASE) or receivers adding thermal noise. The noise reduction by the E/O-converter is demonstrated in Fig. 2 , where the penalty as function of the input power to an EDFA is shown for the case with and without a converter following the EDFA. In this experiment, a 2.5-Gbit/s signal is converted from 1555 to $1557 \mathrm{~nm}$. As seen, the E/O-converter allows $5 \mathrm{~dB}$ lower input power to the EDFA (@1 dB penalty). Replacing the $\mathrm{E} / \mathrm{O}$-converter with an all-optical converter results in a further improvement of $1 \mathrm{~dB}$ due to a steeper transfer function of the latter.

The transfer function of a wavelength-converting regenerator can be made steeper by cascading two converters, and thereby improving the reshaping. Figure 2 also gives the experimental results when the EDFA is succeeded by two all-optical converters. In this case an almost $8 \mathrm{~dB}$ lower input power to the EDFA is possible @ $1 \mathrm{~dB}$ penalty. The measured distributions for marks and spaces after the EDFA and after the two converters are shown in Fig. 3. A clear redistribution of the noise after the converters is seen and when thermal noise is added in the receiver this redistribution results in a lower penalty. A model that takes the redistribution into account has been developed and the results (also given in Fig. 2) show very good agreement with experiments.

In summary, we have demonstrated and compared the reshaping capability of $\mathrm{E} / \mathrm{O}$ and all optical wavelength converters. Besides being compact and featuring low power consumption, the all-optical converter have the best regenerative capability. Finally, we have demonstrated that the noise reduction can be further improved by cascading converters, which is considered to be practical only for the all-optical implementation due to its compactness.

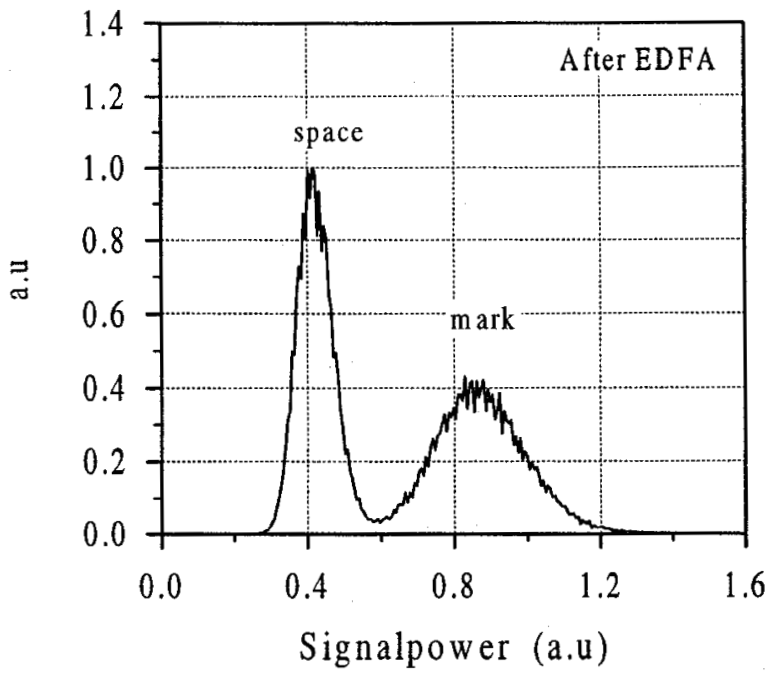

(a)

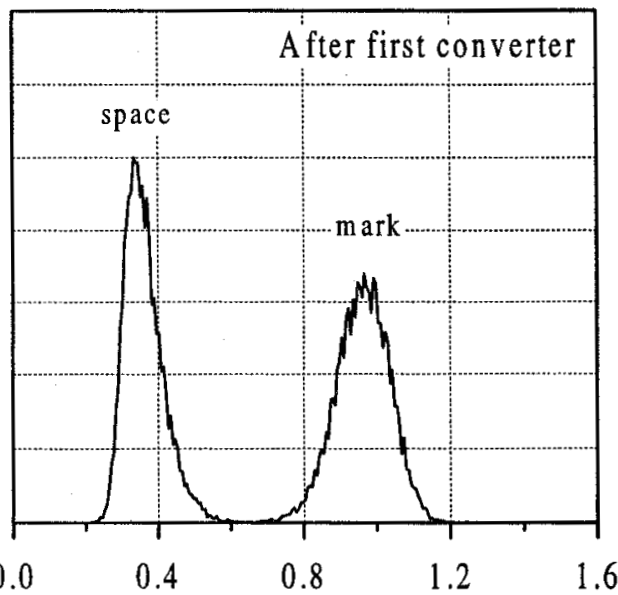

Signalpower (a.u)

(b)

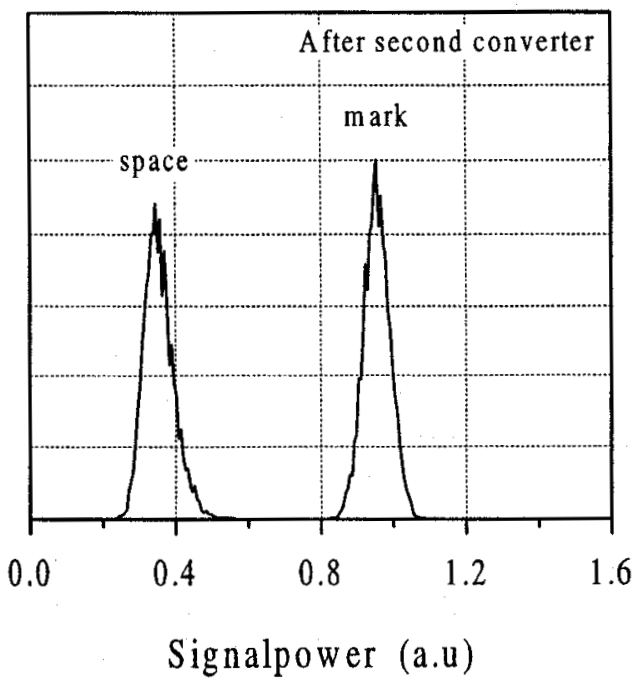

(c)

WB3 Fig. 3. Measured distributions for marks and spaces after the EDFA and after the EDFA followed by one and two $\mathrm{A} / \mathrm{O}$-converters, respectively. Input power to the EDFA correspond to $1 \mathrm{~dB}$ penalty with the EDFA alone $(-31 \mathrm{dBm})$. 
1. T. Durhuus et al., IEEE J. Lightwave Technol. 14, 942-954 (1996).

2. F. Ratovelomanana et al., in Optical Fiber Communication Conference, Vol. 2 of 1996 OSA Technical Digest Series (Optical Society of America, Washington, D.C., 1996), paper WG3.

3. P. Öhlen et al., Electron. Lett. 9, 1011-1013 (1997).

4. B. Mikkelsen et al., Electron. Lett. 32, 566-567 (1996).

\section{Efficient wavelength conversion based on difference frequency mixing in $\mathrm{LiNbO}_{3}$ waveguides with integrated coupling structures}

\section{M.H. Chou, J. Hauden,* M.A. Arbore, M.M. Fejer, E.L. Ginzton Laboratory, Stanford University, Stanford, California 94305; \\ E-mail: choumh@leland.stanford.edu}

Wavelength conversion is a useful function required for wavelengthdivision multiplexed (WDM) networks. ${ }^{1}$ Among numerous wavelengthconversion technologies, difference-frequency mixing (DFM) is attractive because it offers strict transparency to amplitude, frequency, and phase information, excess-noise-free and chirp-reversed signal output, extremely high input dynamic range and a bit rate limited only by the extremely wide parametric conversion bandwidth. ${ }^{2}$ DFM-based devices can also convert multiple wavelengths simultaneously. Wavelength conversion using DFM in $\mathrm{AlGaAs}^{3}$ and annealed proton exchanged $\mathrm{LiNbO}_{3}{ }^{4}$ waveguides has been demonstrated. One practical issue is the low efficiency, 17-dB conversion loss with a 90-nm conversion bandwidth for 65 $\mathrm{mW}$ of pump power. ${ }^{3}$ Another critical problem with guided-wave DFM is the launching of short-wavelength (typically half the signal wavelength) pump light into the fundamental mode of a multimoded (at the pump wavelength) waveguide required for confining a single mode of the signal. In this paper, we address the mode launching problem using integrated mode coupling structures, resulting in mixing efficiency, normalized to the pump power, of $259 \% / \mathrm{W}$ and wavelength conversion loss of $7 \mathrm{~dB}$.

Our integrated waveguide structure is shown in Fig. 1. Pump light is coupled into a single-mode waveguide (mode filter). A subsequent adiabatic taper ${ }^{5}$ permits efficient coupling of the pump radiation into the fundamental mode of the highly multimoded (at the pump wavelength) waveguide, which is optimized for wavelength conversion. The signal is routed into the wavelength conversion region with a directional coupler. Both the mode filter and the taper are implemented using periodically

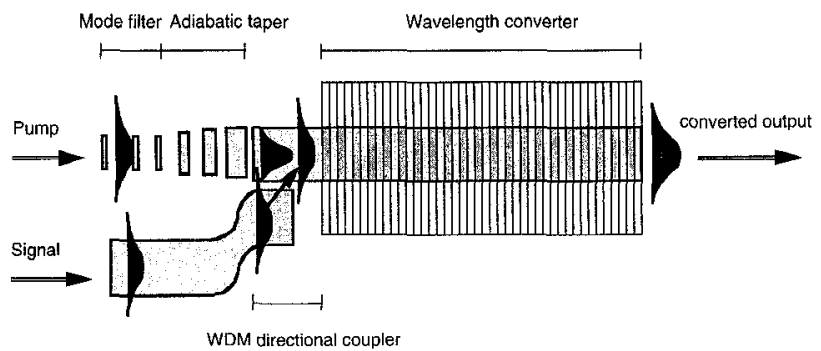

WB4 Fig. 1. Schematic of integrated waveguide structure. A mode filter and an adiabatic taper, both implemented with periodically segmented waveguides, couple the pump into the fundamental mode of a waveguide, which is multimoded at the pump wavelength and was designed for single-mode operation of the signal wavelength and for efficient wavelength conversion. A directional coupler routes the signal into the single-moded wavelength conversion region.

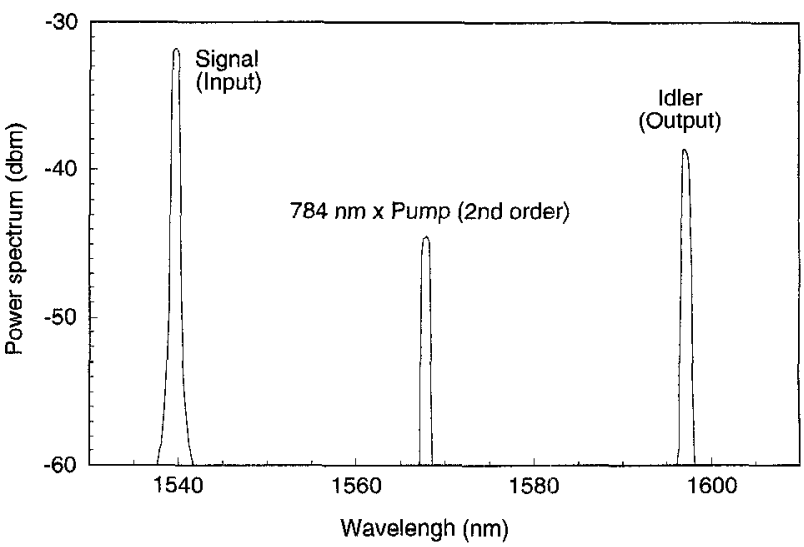

WB4 Fig. 2. Measured optical spectrum on a logarithmic scale for a signal at $1539 \mathrm{~nm}$ and its converted output, which has been shifted $58 \mathrm{~nm}$ to $1597 \mathrm{~nm}$. The central peak at $1568 \mathrm{~nm}$ is the second-order spectrometer response of the pump wavelength of $784 \mathrm{~nm}$. The wavelength conversion loss is $7 \mathrm{~dB}$, corresponding to a internal mixing efficiency of $\sim 259 \% / \mathrm{W}$. (After correction for waveguide propagation losses and Fresnel losses.)

segmented waveguides, allowing for independent optimization of each section.

The samples were fabricated on a 3-inch-diameter wafer of $\mathrm{LiNbO}_{3}$ periodically poled with a $14.5-\mu \mathrm{m}$ period. Waveguides were formed by proton exchange to an exchange depth of $0.55 \mu \mathrm{m}$, followed by annealing at $333^{\circ} \mathrm{C}$ for nine hours. The integrated device consists of a $2.5-\mathrm{mm}$-long mode filter (with segmentation duty cycle of $35 \%$ ), a 5 -mm-long periodically-segmented taper, a $1.5-\mathrm{mm}$-long directional coupler, and a 30-mm-long wavelength converter. The theoretical internal conversion efficiency of this device, neglecting propagation losses, is $-800 \% / \mathrm{W}$, while characterization by second-harmonic generation ( $\mathrm{SHG}$ ) yielded $270 \% / \mathrm{W}$ and a bandwidth 1.3 times the theoretical calculation, indicating nonideal waveguide uniformity.

Static wavelength conversion tests were performed using a cw Tisapphire laser at $784 \mathrm{~nm}$ for the pump and a cw tunable erbium-doped fiber laser for the signal. During the measurement, the sample was maintained at $60-90^{\circ} \mathrm{C}$. Figure 2 shows a measured optical spectrum for a signal at $1539 \mathrm{~nm}$ and its converted output, which has been shifted by $58 \mathrm{~nm}$ to $1597 \mathrm{~nm}$. With $67 \mathrm{~mW}$ of pump power exiting the waveguide, we observed a stable wavelength conversion loss of $7 \mathrm{~dB}$, corresponding to a mixing efficiency of $259 \% / \mathrm{W}$ (assuming $0.4-\mathrm{dB} / \mathrm{cm}$ propagation

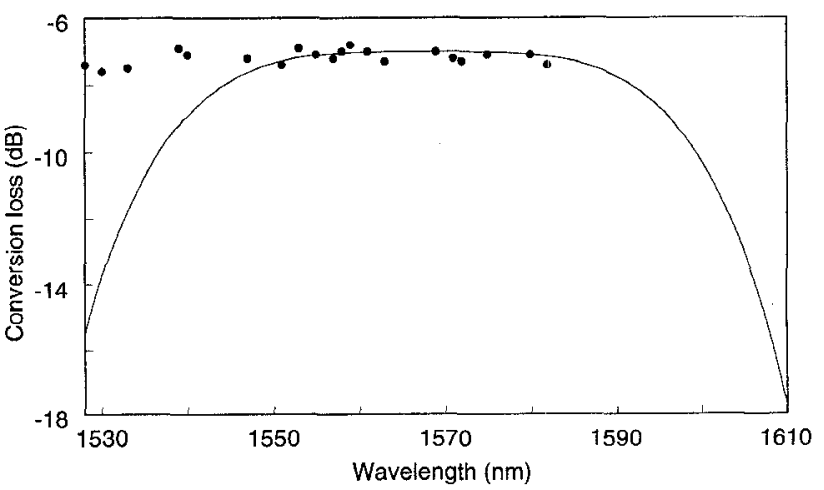

WB4 Fig. 3. Conversion loss curve as a function of input wavelength. The closed circles are the measured results, the solid line is the theoretical calculation. The measured conversion bandwidth is wider than the theoretical calculation due to nonideal waveguide uniformity. 